\title{
Study on the Penetration Strategy of Mathematics Culture based on the Target of Interest Stimulation
}

\author{
Yuan Chang ${ }^{1, a}$ \\ ${ }^{1}$ Shaanxi Institute of International Trade \& Commerce, Xi'an, Shaanxi, 712046 \\ ${ }^{a}$ email
}

Keywords: Penetration Strategy, Mathematics Culture, Interest Simulation

\begin{abstract}
It has been whether or mathematics educator frontline teachers are concerned about the study of mathematics learning interests. But the status of mathematics learning now is not very optimistic. In the eyes of high school students of mathematics is rigorous mathematical proof and math, students feel boring, and gradually getting bored mathematics, mathematics exclusion. So how to arouse students' interest in mathematics is a problem worthy of study. Mathematics learning is mainly reflected in the teaching of mathematics, mathematics teaching on the mathematics classroom to show. If it based on mathematical teaching mathematics under the cultural background in mathematics textbooks mining culture, history of mathematics knowledge, beauty of mathematics, mathematics knowledge and strategic knowledge in mathematics classroom, you can either make the class interesting, easy to understand, and it helps to stimulate students interest in learning mathematics, can also promote students' understanding of mathematics and mathematical culture.
\end{abstract}

\section{Introduction}

The educational value of mathematics culture, the most intuitive is reflected in mathematics teaching. Integration of mathematical culture in the teaching of mathematics, both for teachers and for students, can be the object of Mathematics Education well presented. Huang Qinan stressed: "For teachers and students, the concept of the formation of mathematics culture to open wider view of mathematics and scientific outlook; proper Mathematics Culture helps to accurately locate mathematics curriculum; mathematics culturally appropriate and accurate positioning, there . Litie An aid in mathematics teaching "mathematical cultural and educational Implication of cultural meaning" from the perspective of the students said: "the culture of mathematics education can broaden their horizons and go beyond the spirit of self-space; teaching mathematics culture can promote the formation and development of students overall cognitive structure; mathematics culture can develop and enhance students' scientific literacy mathematics education tomorrow, "stressed:" the purpose of mathematics education and teaching is to enable students to get the necessary "Professor Zhang Dianzhou in." mathematical quality, ability in mathematics, language, calculus and technology can be improved. "This means that students will become mathematics and cultural qualities of the main objectives in the pursuit of mathematics education. according to the author studied the object, so that the in mathematics teaching in secondary schools should be to play the role of mathematics and cultural value of mathematics education, mathematics culture into the classroom, will be able to guide students to use mathematical knowledge learned in daily life, production, effectively solve problems, improve math the ability to appreciate mathematics comes from life, and life with it; the most important thing is to learn mathematics culture, can stimulate students' interest in learning mathematics, truth-seeking spirit and the ability to create culture allows students to explore a new mathematics. Understanding and in essence up sentiment beauty of mathematics. Mathematics people's ideas, thinking and behavior to develop a very important impact, though subtle, but yet is indeed there, and mathematics is no longer changing all the time our lives. mathematics culture in mathematics education in an important position, it can be said mathematical culture in teaching mathematics is very worthy of study. the new curriculum standards also put forward the corresponding requirements of mathematics culture. 


\section{Necessity of Mathematics Culture in Mathematics Teaching}

Now promote student-centered teaching, new curriculum standards to strengthen the teaching of Mathematics Students' Mathematical Thinking. Secondary vocational school students after graduation will not work in mathematics, basic work will not use mathematical formulas or theorems, but they form in the school learning process mathematical thinking, mathematical thinking will be reflected in the work - thinking of rigor, clarity, logic, continued tightness. During the penetration professor of mathematical knowledge to students in mathematics culture, imperceptibly cultivate students' mathematical quality is more important than teaching students mathematical knowledge itself.

Any one of science are actually a creation of history, of course, mathematics also send samples. From Babylon had started with 60 binary system of notation to Euclidean geometry, Newton, Leibniz learn the essence of Descartes to build analytic geometry calculus theory, every time the sublimation of thought, Creative thinking. So mathematics was once called the "creative arts." Where everyday teaching, we should explore the hidden mathematical culture of innovation, and to encourage students to dare to question, dare to innovate, to have creative to solve everyday living and learning in a variety of problems.

Now teaching is student-centered, promote students' self-management, self-learning. Culture is not a simple mathematics from the books will be able to see, usually students have some knowledge and ability and theoretical basis, through independent learning to appreciate, I came to realize. As long as teachers reasonable design in the classroom, with a purpose to infiltrate mathematical culture, to enable students to appreciate the exploring learning and cultural knowledge of the process, we found fun to focus on guiding students to wash hands, love to explore more participation, used to go to make problem, identify problems, solve problems, through such cultural infiltration mathematics, students learn how to learn so that they become the masters of learning.

\section{Teaching Strategies of Mathematical Culture into Classroom and Methods of Teaching Mode}

In teaching, mathematics has a lot of cultural studies, fully explain the importance of integrating mathematics teaching mathematics culture, so far, there are many teachers began to try teaching mathematics culture, some high schools have opened special courses related to mathematics culture, so that the mathematical culture into each middle school mathematics classroom teaching task will become teachers is imperative. Many studies show that mathematical culture of inclusion, not only to enhance the interest of students, and allow students to learn more mathematical knowledge to enrich the mind, broaden their horizons.

Discovery method of teaching is the "discovery learning" methods of teaching. The so-called discovery learning, that students are not getting a concept or principle from the teacher tells, but in the teachers' organizations learning environment, students through their own minds personally a method of acquiring knowledge. Bruner believes that both the students independently explore learning, teachers or guidance of learning, can exercise their thinking, so that students Dynegy to develop effective means peak. The fundamental purpose of discovery learning that students learn knowledge, develop their thinking skills, develop independent thinking and innovation.

The famous mathematics education right that the general thrust is that students of Mathematics Teaching Methods "re-creation." Freudenthal believes that mathematics is a branch of science easiest to create, everyone can re-create mathematical knowledge according to their own characteristics, the "mathematical reality" that everyone is not the same, so the results can be different levels. In teaching, the teacher's task is to provide students with adequate space for students to be able to freely play their thinking imagination. In the actual mathematics teaching, teachers can inspire students from mathematics practical value and charm of its own two baking mathematics mathematical "re-creation." Value of mathematical knowledge in the social life of the production process, is the best material to stimulate students to learn mathematics. In the classroom, teachers can actually practical problems introducing new knowledge, inspire students to re-create motivation. For example, the first day textbooks graphics know this content, teachers can take some 
daily utensils to show the graphic, and then let the students to think, to discover what they perceived graphics. Stimulate students' interest in learning. Another example is to introduce the concept of positive and negative numbers, etc. by a thermometer. In general, the conjecture is the first step to create mathematics. Traditional mathematics teaching results-oriented knowledge, develop logical ability rarely, suppose this step does not exist. This means student creative ability is lacking. In education, induction and analogy are two ways students easy to accept, but also often used method. For example, junior high school when a fractional this content, guide students learned and Fractional and Primary scores analogy, so many of the conclusions of law with respect to fractional re-creation by the students derived. In mathematics teaching, it allows students to use their mathematical knowledge to specific questions to establish a new mathematical model that allows students to learn mathematics.

Activity teaching methods for secondary school students during class cannot concentrate, scattered, restless in class features, taken outside explicit awareness activities to attract students to actively participate, then the inside of cognitive activity, the formation of a teaching model. Depending on the functional activities can be divided into three categories, the organization of cognitive activities, stimulate learning interest and motivation and activities feedback correction learning activities. The first organization of cognitive activities, mainly referring to the teachers according to the principles of cognitive theory, organizing student perception, exploration and practice of operational knowledge, help students to meaningfully interpret new knowledge or achieve a kind of knowledge interrelated cognitive activity. For example, the study "parallel lines equally divided segments theorem", the teacher can give a student a toothpick or match, requiring students to use notebook already printed equidistant parallel lines, looking equal parts the point of a toothpick and a ruler measurements for verification. The second stimulate interest in learning and motivation activities. For example, in learning "similar items" when allowing students to do a "find a friend" of the game, before class teacher prepared cards similar items, and then distributed to students, and then have a go with their students are of similar items friends, sit together after the find, the other is "squeezed out" of the students stood up and find their friends again. This classroom students can actively participate in, students can better grasp of mathematical knowledge. The third is the feedback correction learning activities, mainly refers to the process of teaching in the classroom, the teacher or the students themselves check to check a class learning activities. For example, after doing exercises in the classroom, the students raise their hands to answer a teacher or a student case each packet inspection.

Exercise is teaching traditional teaching methods, mainly referring to teachers for teaching in the basics and explain the focus of the analysis, the system, and then through a teaching strategy for students to practice basic training. The main steps are generally new knowledge, to explain instances, students practice, feedback. "Succinctly and training" and "a lot of training" is the typical way of teaching exercises, the advantages of teaching is to maintain the consistency of the teachers to teach knowledge and action, the teacher is easier to control the teaching process and order, on the basis of student more solid knowledge and basic training, but students in the face of such a long time classes, students' interest in learning have a greater impact, will affect the enthusiasm of students to learn mathematics, so that students formed a "mathematics teacher demonstration copy is problem-solving methods "mistaken view, and even fear of negative attitudes mathematics. And do not help students analyze and solve problems and creative skills. So this need to improve teaching and research.

\section{Conclusion}

Mathematical culture into mathematics teaching, not only can increase the fun of mathematical knowledge to enrich the mathematics classroom, but also to stimulate students' interest in learning mathematics, so that students learn at the same time, the idea of the nature of mathematics, feel the value of mathematics and charm. Some passive to active learning math students learn math, soon to be "to me" to "I want to learn." Students learn cultural knowledge of mathematics, mathematics more colorful areas of understanding, broaden their horizons. Teachers hope the people in the front 
line of the struggle, more learning, more research, and strive to cultivate thousands of mathematical talent, contributing to various fields. The future of mathematics teaching is also a connotation in mathematics, mathematics associated with each field will be more attention. Mathematics teaching culturally appropriate moderate integration is inevitable. Purpose is to enable students in the mathematics classroom can easily learn.

\section{Acknowledgements}

The practical study to improve students' interest to learn higher mathematics by adopting mathematical culture. Project number JG201514.

\section{References}

[1] Heymann.HW. Allgemeinbilding and Mathematics [M]. Weinhein-Basel: Belz, 1996: 4-59.

[2] Zhang Xiong C, Huang Xiang. Comparative Analysis of Chinese and American high school mathematics curriculum goals and the Enlightenment [J]. Mathematical communication, 2004, 21.

[3] Tang Ruifen. Selection of Mathematics Teaching Theory [M]. Shanghai: East China Normal University Press .2001, 1.

[4] Shi Xunzhong. The creation of loyal mathematics classroom - Mathematics recreation of teaching strategies [J]. Mathematics Education. 1999.

[5] Weizhong, Xu Xiaofang. Design Review: Case-based teaching mathematics culture [J]. Zhejiang Normal University (Natural Science Edition) (2008) (9): 248-250. 